\title{
Annontations
}

\section{Changing concepts in asthma}

It is generally accepted that in acute asthmatic attacks the child has greater difficulty breathing out than breathing in, and that when airways obstruction is severe, positive intrathoracic pressures are generated with the help of the accessory, respiratory muscles. Mead introduced the concept of dynamic compression of the airway indicating that these expiratory efforts are not entirely helpful, as positive, intrathoracic pressures will tend to collapse the relatively compliant airways proximal to the obstruction, further increasing the bronchoconstriction. ${ }^{1}$ This concept has been supported by measurements on models, and by the observation that chest $x$-rays taken during expiration show a considerable reduction in the diameter of the intrathoracic airway when severe airways obstruction is present. It is also well established that the lung volume tends to rise as airways obstruction increases, so that the volume of air in the lungs at the end of each breath may be doubled or even trebled. ${ }^{2}$ It has been assumed that this is a purely physical response of the respiratory system to conditions in which the flow time constant during expiration is greatly prolonged relative to inspiration, resulting in a tendency for the lungs to be pumped up to a higher level. This increase in lung volume is of advantage to the child. Although he will have to work harder on inspiration in order to expand his already stretched lungs, this work is stored in the elastic tissue of the lungs and is available to help expel the air during the next expiration. Breathing at a higher lung volume also tends to stretch open the airways and so reduces the degree of airway obstruction.

There is now some information to suggest that this is not purely a physical process, but that changes occur in the elastic recoil characteristics of the lungs and chest wall to favour expansion of the thorax to a higher resting lung volume. ${ }^{3}$

Some doubt has also been cast on the whole concept of dynamic compression and positive intrathoracic pressures as a result of recent work. ${ }^{4}$ In this work measurements were taken of the intrathoracic pressure changes during tidal breathing and also during forced respiratory manoeuvres in 8 normal children and 8 children with acute asthma between the ages of 11 and 14. The intrathoracic pressure was monitored using an oesophageal balloon system. It was found that as the severity of the attacks increased, as judged by the $\mathrm{FEV}_{1}$, the mean inspiratory pressure fell progressively, so that during tidal breathing the mean intrathoracic pressure was $-15 \cdot 7 \mathrm{~cm} \mathrm{H}_{2} \mathrm{O}$ in the asthmatic children, compared with $-5.0 \mathrm{~cm}$ in the normal children. The peak inspiratory pressures during tidal breathing reached a mean of $-28.8 \mathrm{~cm} \mathrm{H}_{8} \mathrm{O}$ in the asthmatic group, compared with only $-7.0 \mathrm{~cm}$ in the controls. Surprisingly, in the presence of airways obstruction the mean maximum pressure on expiration during tidal respiration was only $-1.7 \mathrm{~cm} \mathrm{H}_{2} \mathrm{O}$, while in the most severe attacks only small positive intrathoracic pressures were detected. During maximum respiratory efforts the asthmatic children generated intrathoracic pressures of $-38.8 \mathrm{~cm} \mathrm{H}_{2} \mathrm{O}$, compared with $-26 \cdot 1$ in the normal subjects. This finding is interesting for two reasons. Firstly if these data are representative, our concepts of the dynamic changes occurring in the airways during an asthmatic attack need to be reconsidered. Of greater interest perhaps are the clinical implications. A fall in the mean intrathoracic pressure will increase the hydrostatic factors tending to transfer fluid from the pulmonary capillary bed to the interstitial tissues, effectively producing pulmonary oedema. These authors have already shown that this transfer of fluid can be produced in dogs subjected to large negative intrathoracic pressures. ${ }^{4}$ They claim that the peribronchial cuffs of oedema, apparent at necropsy, are almost certainly brought about by this mechanism. Their conclusion from the data is that although intravenous fluids are indicated to correct dehydration, over-generous administration of fluids will reduce the pulmonary capillary hydrostatic pressure and augment the transfer of fluid to the interstitial tissues, thereby resulting in a further deterioration in the child's clinical state.

As these data conflict with the clinical impression that high positive intrathoracic pressures are generated, it is important that they should be reviewed critically. Absolute intrathoracic pressures are difficult to measure accurately as artificial baselines tend to be generated by the tone of the oesophagus and also by the elastic recoil characteristics of the balloon. The size of the changes measured by these authors is, however, probably too great to be 
attributed to artefacts alone. Alternatively it may be that these asthmatic children, who are breathing through a mouthpiece, have a tube down one nostril and are wearing noseclips, are breathing in an unrepresentative manner, and are not generating positive intrathoracic pressures as a result of this. This work obviously needs to be repeated, but meanwhile it would seem reasonable to avoid overhydrating children with status asthmaticus.

\section{References}

${ }^{1}$ Mead, J. (1973). Respiration; pulmonary mechanics. Annual Review of Physiology, 35, 169-192.

${ }^{2}$ Engström, I. (1964). Respiratory studies on children. XI.
Mechanics of breathing, lung volumes and ventilatory capacity in asthmatic children from attacks to symptomfree status. Acta paediatrica Scandinavica. Supplement, $155,1-60$.

${ }^{3}$ Peress, L., Sybrecht, G., and Macklem, P. T. (1976). The mechanism of increase in total lung capacity during acute asthma. American Journal of Medicine, 61, 165-169.

${ }^{4}$ Stalcup, S. A., and Mellins, R. B. (1977). Mechanical tones producing pulmonary edema in acute asthma. New England Journal of Medicine, 297, 592-596.

A. D. MiLner Department of Child Health, University Hospital and Medical School, Clifton Boulevard, Nottingham NG7 2UH 